\title{
A esterilização de mulheres de baixa renda em região metropolitana do sudeste do Brasil e fatores ligados à sua prevalência*
}

\author{
Female sterilization among low income women in a metropolitan region of \\ southeastern Brazil and factors related to its prevalence
}

\author{
Elisabeth Meloni Vieira**
}

\begin{abstract}
VIEIRA, E. M. A esterilização de mulheres de baixa renda em região metropolitana do sudeste do Brasil e fatores ligados à sua prevalência. Rev. Saúde Pública, 28: 440-8, 1994. Estudo realizado na região metropolitana de São Paulo, Brasil, entre marçoe julho de 1992, entre 3.149 mulheres de baixa renda com idade entre 15 e 49 anos, mostrou que $21,8 \%$ estavam esterilizadas. Entre as mulheres unidas, $29,2 \%$ estavam esterilizadas e $34,4 \%$ usavam a pílula. Quatrocentos e sete mulheres esterilizadas abaixo dos 40 anos, que haviam se submetido à cirurgia há pelo menos um ano antes da data da entrevista, foram perguntadas sobre sua história reprodutiva, uso prévio de métodos anticoncepcionais, o processo de decisão para esterilizar-se, o acesso à esterilização e à adaptação após o procedimento. Os resultados mostraram que mesmo para as mulheres de baixa renda o acesso à esterilização é regulado pelo pagamento ao médico. A baixa qualidade e cobertura das atividades de planejamento familiar do Programa de Assistência Integral à Saúde da Mulher, assim como a ausência de regulamentação, está provavelmente contribuindo para a escolha da esterilização feminina por mulheres jovens. A forma que a esterilização tem sido realizada fere preceitos éticos. O estudo mostra que a irreversibilidade do procedimento não foi adequadamente entendida por quase $40 \%$ das mulheres esterilizadas. Discute-se a aceitabilidade da esterilização como resultado de uma estratégia social complexa com o envolvimento de vários setores da sociedade brasileira aliada à necessidade de regulação da fertilidade das mulheres. A necessidade de regular e controlar o procedimento também é discutida. A regulamentação criaria condições mais justas de acesso à esterilização para as mulheres de baixa renda e poderia salvaguardar aspectos éticos na sua escolha.
\end{abstract}

Descritores: Esterilização tubária, estatística. Planejamento familiar, métodos. Saúde da mulher.

\section{Introdução}

A esterilização feminina é atualmente o método anticoncepcional mais usado entre as mulheres brasileiras de 15 a 49 anos $(29,3 \%)$ e o segundo método mais usado entre as mulheres que residem em São Paulo (30,7\%) (Oliveira e Simões $\left.{ }^{21}, 1988\right)$. O aumento de sua prevalência foi intenso durante a década de 80 , a despeito da implantação do Programa de Assistência Integral à Saúde da Mulher (PAISM), pelo Ministério da Saúde, em 1984. Esse programa, entre outras atividades, prevê a oferta, supervisão

\footnotetext{
* Baseado em estudo financiado pela Organização Mundial da Saúde: "O arrependimento após a esterilização feminina em mulheres de baixa renda em São Paulo, Brasil".

** Secretaria de Estado da Saúde de São Paulo - São Paulo, SP - Brasil-Bolsista do Banco Mundial e CNPqBrasília, DF-Brasil

Separatas/Reprints: E.M.Vieira - Rua Santo Antonio, 590 01314-000-São Paulo, SP - Brasil

Edição subvencionada pela FAPESP. Processo 94/0500-0
}

médica e orientação de diversos métodos anticoncepcionais reversíveis.

Muitos problemas têm sido apontados nas atividades de planejamento familiar nos centros de saúde do serviço público, entre eles a flutuação na provisão de métodos, a ausência de profissionais treinados para essa atividade e a desinformação geral entre os proficionais sobre essa atividade programática (Villela e col., ${ }^{23} 1988$; Osis e col..$^{22}$, 1991).

A deficiência na oferta de métodos anticoncepcionais tem sido apontada como um fator importante que influencia a alta demanda da esterilização feminina no país (Berquós ${ }^{5}$ 1989). Alia-se a esta situação a ilegalidade e risco do aborto clandestino.

Vários "setores" da sociedade têm estimulado o uso da esterilização feminina e compõem uma estratégia social das mais relevantes para a efetiva prevalência da esterilização feminina. Fazem parte dessa estratégia:

-Médicos, pricipalmente ginecologistas e obstetras que a realizam. 
- Clínicas privadas de planejamento familiar que difundiram no país a oferta da esterilização e que oferecem, principalmente aos pobres, a esteri1ização grátis,em alguns Estados brasileiros (Janowitz e col. ${ }^{17}$, 1985; Lassner e col. ${ }^{18}, 1986$ ).

- Companhias e empregadores que têm estimulado casais à esterilização oferecendo empréstimo financeiro para custear a operação.

- Políticos em campanhas eleitorais que oferecem a esterilização gratuita em troca de votos e apoio popular (Assembléia Legislativa do Estado de Goiás ${ }^{3}$, 1992; Hardy e col. ${ }^{14}$, 1992; Assembléia Legislativa do Estado do Rio de Janeiro $^{2}, 1991$ ).

Os médicos ocupam papel importante nessa estratégia em disseminar a esterilização, não apenas porque efetivamente a realizam, mas porque através das escolas de medicina, hospitaisescolas e da prática diária influenciam outros profissionais e estudantes dessa área. Os médicos são também as pessoas de ligação entre as clínicas privadas de planejamento familiar, o serviço público e as universidades. Estimou-se que 20 milhões de dólares foram investidos em clínicas de planejamento familiar entre 1978 e 1984 (Conselho Estadual da Condição Feminina do Estado de São Paulo ${ }^{10}, 1986$ ). Embora estas clínicas privadas não tenham sido responsáveis pela maioria das esterilizações, de acordo com os dados da FIBGE/PNAD, 1986, conforme Oliveira e Simões ${ }^{21}$ (1988) sua influência é considerável já que trabalham em cooperacão com universidades e serviços públicos em vários Estados (Haws e col. ${ }^{15}, 1992$ ).

$A$ ausência de normas que regulamentam a esterilização, é provavelmente outro fator estimulador da disseminação da esterilização, já que facilita a clandestinidade em que esta é praticada. O Conselho Federal de Medicina e suas regionais não recomendam a esterilização baseando-se na ausência de regulamentação, ou mesmo na ilegalidade do procedimento (Conselho Regional de Medicina do Estado de São Paulo'1, 1988*). Vários projetos de leis para regulamentar o procedimento têm sido propostos há alguns anos na Câmara Federal (Aguinaga e Schiavo', 1991). Em junho de 1994 o projeto de regulamentação do procedimento foi aprovado na Câmara Federal devendo agora ser julgado no Senado (revista $V e j a^{12}$, 1994).

A situação acima descrita faz com que a oferta da esterilização seja muito distinta de outros países. $\mathrm{O}$ forte elemento medicalizador do planejamento familiar, no Brasil, distorce a

* Cite-se também resposta à carta-consulta, de novembro de 1992 pelo Conselho Regional de Medicina. prevalência de uso de métodos anticoncepcionais criando uma situação curiosa, na qual os dois métodos mais usados são de alta eficácia (esterilização feminina e pílula). O terceiro e quarto métodos mais usados são, respectivamente, o método de abstinência periódica e o coito interrompido, anticoncepcionais típicos de lugares e épocas onde a tecnologia médica não está disponível.

$O$ presente artigo analisa o modo que a esterilização feminina tem sido oferecida no Estado de São Paulo, os motivos que levam as mulheres de baixa renda a escolher este método, os fatores associados à idade ao esterilizar-se e o nível de informação das mulheres esterilizadas. Esta análise é baseada nos resultados de um estudo realizado em áreas pobres da Região Metropolitana de São Paulo.

\section{Material e Método}

Dois municípios, Mauá e Osasco, foram previamente selecionados utilizando-se alguns indicadores demográficos e critérios que pudessem afetar a prevalência da esterilização, seu modo de oferta e a adaptação após a cirurgia. Considerou-se como critérios para a seleção das áreas: a taxa de natalidade, o coeficiente de mortalidade infantil, o indice de cesarianas e a taxa de fecundidade que mais se aproximassem dos índices do Estado; características urbanas (o que excluiu as áreas da Região Metropolitana na fronteira com o Estado); a presença de hospital e maternidade na área, ou de fácil acesso (30 min. de transporte coletivo urbano); presença do PAISM com atividades de planejamento familiar implantadas e ausência de clínicas privadas de planejamento familiar que oferecessem a esterilização.

As áreas pobres dos dois municípios foram mapeadas, visitadas e definidas em setores. Selecionou-se ao acaso as ruas e cada uma delas foi considerada um aglomerado. Visitou-se, no mínimo duas e no máximo até três vezes, um total de 45 ruas, 34 em Mauá e 11 em Osasco. As visitas foram realizadas pelo menos uma vez durante a semana e um dos dias do fim de semana. Todas as mulheres de 15 a 49 anos que residissem nos domicílios daquelas ruas e estivessem presentes no momento da visita foram entrevistadas sobre 0 uso de métodos anticoncepcionais. A todas as mulheres esterilizadas, com menos de 40 anos, e que tivessem sido operadas há pelo menos um ano antes da data da entrevista, aplicou-se um questionário estruturado sobre sua vida reprodutiva, uso prévio de anticoncepcionais, 
decisão de submeter-se à esterilização e sua posterior adaptação a este método.

Noventa e oito relatos espontâneos foram registrados durante as entrevistas e analisados, usando-se o método qualitativo de análise de conteúdo. Esse também foi utilizado para a análise de 17 entrevistas em profundidade, utilizando-se um roteiro e gravador.

Os dados quantitativos foram computados e analisados utilizando-se o programa estatístico para Ciências Sociais (SPSS/PC+). A análise bivariada foi feita através do teste de associação do Qui-quadrado entre as variáveis nominais; entre as variáveis nominais e de intervalo foram utilizados o teste $t$ de comparação das médias. A hipótese nula foi rejeitada quando o nível de significância foi menor que 0,05 .

\section{Resultados}

Um total de 3.384 (89\%) domicílios foram visitados, apenas 409 (11\%) foram encontrados fechados durante todas as visitas. Foram registradas como vivendo nesses domicílios 4.976 mulheres de 15 a 49 anos. Um total de 3.149 mulheres na idade reprodutiva (15 a 49 anos) foram entrevistadas sobre o uso de métodos anticoncepcionais. Entre elas foram encontradas 688 mulheres esterilizadas $(21,8 \%), 407$ (13\%) estavam abaixo dos 40 anos e haviam sido esterilizadas há pelo menos um ano antes da data da entrevista. Apenas $2,9 \%$ recusaramse a ser entrevistadas.

Nenhuma diferença significativa foi encontrada na distribuição etária da amostra comparada à população de mulheres na idade reprodutiva vivendo na Região Metropolitana. Não foi encontrada nenhuma diferença significativa entre o grupo de 2.254 mulheres que residiam em Mauá comparado com o grupo de 895 mulheres que residiam em Osasco em relação às variáveis consideradas (número de pessoas residindo no domicílio, número de mulheres em idade reprodutiva residindo no domicílio, união sexual, idade, uso e não-uso de método anticoncepcional, motivos para o não-uso de método e idade na época da esterilização). A classificação em grupos étnicos foi feita pela autoclassificação e pela opinião da entrevistadora, sendo que para ambas houve diferença entre as residentes de Mauá e Osasco. Enquanto em Mauá havia mais mulheres que se consideraram brancas, pretas ou indígenas, em Osasco havia mais mulheres que se consideraram pardas. Não foi encontrada nenhuma associação entre os grupos étnicos e o uso de métodos anticoncepcionais nessas áreas.
As principais características encontradas entre as 407 mulheres esterilizadas: $92,5 \%$ estavam em união conjugal e $87,5 \%$ sempre viveram com o mesmo parceiro, $66 \%$ frequientaram a escola por 4 anos ou menos, apenas $14 \%$ tiveram mais de oito anos de educação formal, $62 \%$ são donasde-casa e a metade das que trabalham fora estavam desenvolvendo atividades relacionadas ao comércio e serviços, como empregada doméstica, manicure, cabelereira ou vendedora de cosméticos ou lingerie a domicílio. A maioria dos maridos das entrevistadas é trabalhador não especializado da indústria e comércio locais. A renda familiar das entrevistadas é menor ou igual a um salário-mínimo per capita, em $64 \%$ dos casos. Não foi encontrada diferença significativa entre essas variáveis e o local de residência.

Sessenta por cento de todas as mulheres de 15 a 49 anos (3.149) usavam método contraceptivo. O método mais usado encontrado foi a pílula, utilizado por $26,1 \%$ das mulheres, seguido pela esterilização feminina, usado por $21,8 \%, 1,1 \%$ usavam método de abstnência periódica e $10,7 \%$ usavam outros métodos.

Entre as mulheres unidas de 15 a 49 anos, $20 \%$ não usavan nenhum método anticoncepcional, $34,4 \%$ usava a pílula, $29,2 \%$ estavam esterilizadas e $16,4 \%$ utilizavam outros métodos (Tabela 1).

\section{O acesso à esterilização}

O acesso à cirurgia foi em sua grande maioria realizado através de pagamento ao médico. Oitenta por cento das mulheres abaixo dos 40 anos pagaram diretamente ao médico para ter a laqueadura e $88 \%$ das cirurgias foram realizadas durante ou imediatamente depois do último parto. $O$ índice de cesarianas encontrado para o último parto foi de $77 \%$, significando que apenas $11 \%$ das cirurgias esterilizadoras foram realizadas por ocasião do parto vaginal. De acordo com as entrevistadas, menos de $10 \%$ das laqueaduras foram realizadas em separado do

Tabela 1. Uso de métodos anticoncepcionais entre muIheres unidas*, Estado de São Paulo, 1986 e Regiāo Metropolitana, 1992.

\begin{tabular}{lcc}
\hline Método & $\begin{array}{c}\text { Est. São Paulo, 1986** } \\
\%\end{array}$ & $\begin{array}{c}\text { Reg. Metrop., } 1992 \\
\%\end{array}$ \\
\hline Não-uso & 30,6 & 20,0 \\
Pílula & 25,7 & 34,4 \\
Esterilização & & \\
feminina & 30,7 & 29,2 \\
Outros & 13,0 & 16,4 \\
\hline Total & 100,0 & 100,0 \\
\hline
\end{tabular}

* Mulheres de 15 e 49 anos

"* Fonte: Oliveira $\theta$ Simōes ${ }^{21}, 1988$ 
Tabela 2. Pagamento da esterilização e motivos de saúde para fazer a laqueadura, Região Metropolitana de São Paulo, 1992.

\begin{tabular}{|c|c|c|c|}
\hline Pagamento & $\begin{array}{c}\text { Refere problemas } \\
\text { de saúde como motivo } \\
\text { para esterilizar-se } \\
\%\end{array}$ & $\begin{array}{c}\text { Năo refere problemas } \\
\text { de saúde como motivo } \\
\text { para esterilizar-se } \\
\%\end{array}$ & $N$ \\
\hline $\begin{array}{l}\text { Esterilização } \\
\text { grátis } \\
\text { Pago pela } \\
\text { cliente }\end{array}$ & $\begin{array}{l}32,8 \\
67,2\end{array}$ & $\begin{array}{l}13,4 \\
86,6\end{array}$ & $\begin{array}{c}79 \\
326\end{array}$ \\
\hline Total & N 128 & 277 & 405 \\
\hline
\end{tabular}

parto e $2,5 \%$ foram realizadas junto com cirurgias ginecológicas variadas, como perineoplastia, cisto de ovário e curetagem.

A maioria das mulheres soube da esterilização através de alguém de suas relações, amigas ou parentes, que fizeram a cirurgia $(37,7 \%)$, um terço $(32 \%)$ soube através de alguém, como parente ou amigas, que the informou sobre a cirurgia, $20 \%$ foran informadas pelo médico, menos de $3 \%$ souberam através da mídia (imprensa e televisão) e $7 \%$ através de palestras, reuniões ou aulas sobre o assunto.

A maioria das esterilizações, $74,7 \%$, foi realizada em hospital privado do Estado de São Paulo, 15,6\% foram feitas em hospitais públicos, $9 \%$ em hospitais de outros Estados e 0,8\% em clínicas privadas de planejamento familiar. A forma de pagamento do parto e da esterilização variou de acordo com o tipo de assistência médica que a cliente tivesse direito. Os casos mais comuns são o pagamento do parto pelo Convênio ou pelo INAMPS e a esterilização paga diretamente ao médico. Foram encontrados dois casos de empréstimo de empregadores para custear a operação, este foi posteriormente descontado do salário do marido mensalmente. Houve um caso de um político em campanha eleitoral que arcou com os custos da operação de umas das entrevistadas.

Quase $20 \%$ das esterilizações foram feitas gratuitamente. Foi encontrada associação entre ter apontado problemas de saúde como motivo e ter obtido a esterilização grátis (Tabela 2).

Tabela 3. Comparação das médias de salários-mínimos per capita entre aquelas que pagaram e as que não pagaram pela esterilização, Região Metropolitana de São Paulo, 1992.

\begin{tabular}{lcrr}
\hline Pagamento & $\mathrm{N}$ & SM/Média & $\mathrm{DP}$ \\
\hline Não pagou & 57 & 0,7614 & 0,838 \\
Pagou & 261 & 1,1104 & 0,976 \\
& & $\mathrm{~T}=-2,51$ & $\mathrm{P}=0,013$ \\
\hline
\end{tabular}

SM - Salário-mínimo

DP - Desvio-padrão
As entrevistadas que não pagaram a cirurgia tinham uma renda familiar per capita significativamente menor do que as que pagaram a cirurgia. Enquanto as que não pagaram, recebiam 0,76 do salário-mínimo, as que pagaram, recebiam 1,1 salário-mínimo (Tabela 3 ).

\section{Número de filhos}

Entre as 407 entrevistadas, o número médio de filhos vivos é 3,1. A idade ao ter o primeiro filho foi, em média, 20,9 anos e a idade mediana 20.

As mulheres com três filhos ou menos fizeram a esterilização mais jovem, tinham maior renda e maior escolaridade do que mulheres com 4 filhos ou mais. Mulheres com três filhos ou menos foram esterilizadas, em média, aos 27,5 anos, relataram renda de 1,19 salários minimos, em média, e freqüentaram a escola por 4,6 anos; enquanto aquelas com quatro filhos ou mais foram, em média, esterilizadas aos 28,7 anos, recebiam uma renda de 0,82 salário-mínimo e freqüentaram a escola por 3,7 anos em média. Mulheres com menor número de filhos tiveram o primeiro filho mais tarde, com 22,1 anos em média, e relataram menor número de falhas* usando métodos anticoncepcionais reversíveis antes da esterilização (média 0,44). Enquanto mulheres com quatro filhos ou mais tiveram o primeiro filho mais jovem (19,1 anos em média), o número médio de falhas durante o uso de métodos reversíveis foi 0,72 (Tabela 4). Esses

Tabela 4. Diferenças entre idade ao primeiro filho, anos de escolaridade, renda, idade ao esterilizar-se e número de falhas usando métodos reversíveis de acordo com paridade, Região Metropolitana, 1992.

\begin{tabular}{|c|c|c|c|}
\hline $\begin{array}{l}\text { Paridade } \\
\text { Idade ao } \\
\text { primeiro filho }\end{array}$ & $\begin{array}{c}3 \text { filhos ou } \\
\text { média } \\
\text { DP }\end{array}$ & $\begin{array}{l}\text { menos } \\
22,1 \\
3,7\end{array}$ & $\begin{array}{c}4 \text { filhos ou mais } \\
19,1 \\
2,6\end{array}$ \\
\hline$T=8,77$ & $P=0,000$ & & \\
\hline $\begin{array}{l}\text { Anos de } \\
\text { escolaridade }\end{array}$ & $\begin{array}{c}\text { média } \\
\text { DP }\end{array}$ & $\begin{array}{l}4,6 \\
2,8\end{array}$ & $\begin{array}{l}3,7 \\
2,7\end{array}$ \\
\hline$T=3,14$ & $P=0,002$ & & \\
\hline $\begin{array}{l}\text { Renda famili } \\
\text { per capita em }\end{array}$ & $\begin{array}{lc}\text { iar } & \text { média } \\
\text { ר SM } & \text { DP }\end{array}$ & $\begin{array}{l}1,19 \\
1,00\end{array}$ & $\begin{array}{l}0,82 \\
0,84\end{array}$ \\
\hline$T=3,41$ & $P=0,001$ & & \\
\hline $\begin{array}{l}\text { Idade ao } \\
\text { esterilizar-se }\end{array}$ & $\begin{array}{l}\text { média } \\
D P\end{array}$ & $\begin{array}{r}27,5 \\
3,8\end{array}$ & $\begin{array}{r}28,7 \\
3,6\end{array}$ \\
\hline$T=-3,08$ & $P=0,002$ & & \\
\hline $\begin{array}{l}\text { Número de } \\
\text { falhas } \\
T=-3,20\end{array}$ & $\begin{array}{c}\text { média } \\
D P \\
P=0,004\end{array}$ & $\begin{array}{l}0,44 \\
0,65\end{array}$ & $\begin{array}{l}0,72 \\
1,05\end{array}$ \\
\hline
\end{tabular}

* Número de falhas, usando métodos reversíveis, foi calculado baseando-se na resposta da entrevistada à pergunta se havia engravidado quando estava usando método reversível, quantas vezes e quais métodos. 
resultados mostram que mesmo entre as mulheres de baixa renda, maior escolaridade e renda estão associadas com menor número de filhos e melhor uso de métodos anticoncepcionais.

\section{Os motivos para esterilizar-se}

A maioria das mulheres $(72,5 \%)$ pediu ao médico para ser esterilizada, a esterilização foi indicada pelo médico para $19 \%$ das entrevistadas e oferecida como escolha para $5,4 \%$ delas. Quatro entrevistadas foram esterilizadas sem o seu consentimento.

O principal motivo apontado pela maioria das entrevistadas (44\%), para terem se submetido à operação foi estar satisfeita com o número de filhos, $26 \%$ afirmaram problemas de saúde, $6,4 \%$ alegaram como motivo ter se submetido a muitas cesáreas, $12,3 \%$ apontaram dificuldade financeira, $5,7 \%$ revelaram que não se adaptavam a outros métodos e $2 \%$ disseram que o marido não queria mais filhos. Entre outros motivos para esterilizarse, dificuldades conjugais, alcoolismo do marido e medo de ter outro filho deficiente, foram citados por $3,7 \%$ das entrevistadas.

\section{O uso prévio de métodos reversiveis}

A grande maioria das mulheres esterilizadas abaixo dos 40 anos (91\%) usou pelo menos um método anticoncepcional reversível antes de ter se submetido à cirurgia. O método mais usado foi a pílula, $84,5 \%$, seguido pelo coito interrompido, $33,2 \%$, o preservativo, $32,4 \%$, e pelo método rítmico ("tabelinha") $13,1 \%$. Nove porcento das entrevistadas revelaram não ter nenhuma experiência anterior com métodos reversíveis antes de esterilização Essas mulheres têm em média menor escolaridade e menor conhecimento sobre os métodos anticoncepcionais quando comparadas com as que utilizaram métodos reversíveis antes da esterilização. Um terço das entrevistadas, $30,4 \%$, usou mais de um método, mas a maioria, $54,3 \%$, usou apenas a pílula. A maioria das entrevistadas, $67,3 \%$, utilizou métodos anticoncepcionais reversíveis apenas depois do nascimento do primeiro filho e o método mais utilizado foi a pílula. Aquelas mulheres que usaram método antes do primeiro filho têm maior escolaridade e menor número de filhos do que aqueles que não utilizaram e essa diferença é estatisticamente significante.

Muitas entrevistadas (44\%) relataram algum tipo de problema enquanto utilizavam um método reversível e o mais citado foram queixas relacionadas à saúde; $43,2 \%$ referem falha de método antes de terem se submetido à esterilização.

\section{A idade ao esterilizar-se}

Para todas as mulheres esterilizadas, de 15 a 49 anos, a idade média da esterilização foi 29,8 e a mediana foi de 29 anos. Para as mulheres abaixo dos 40 anos, a idade média e a mediana foram 28 anos. A maioria das mulheres abaixo dos 40 anos $(46,7 \%)$ foi esterilizada entre 25 e 29 anos, $29 \%$ foram esterilizadas entre 30 e 34 anos, $18 \%$ entre 20 e 24 anos, $6 \%$ entre 35 e 39 anos e $0,5 \%$ abaixo dos 20 anos. Por estes resultados podemos concluir que a esterilização raramente ocorre depois dos 35 anos. A maioria das mulheres (94\%) foi esterilizada antes dessa idade e $65 \%$ antes des 30 anos. Quase um quinto dessas mulheres foi esterilizada antes dos 25 anos.

Mulheres que foram esterilizadas antes dos 30 anos têm maior escolaridade, começaram a vida reprodutiva mais cedo, tiveram menor número de filhos e apresentaram um nível menor de satisfação com a esterilização do aquelas que se submeteram à esterilização depois dos 30 anos (Tabela 5). Ou seja, ao contrário do que se pensa, as mulheres de baixa rende não são esterilizadas jovens porque têm muitos filhos. As mulheres que foram esterilizadas mais jovens têm menor número de filhos do que aquelas esterilizadas depois dos 30 anos, sendo o número de filhos consequiência de ter sido esterilizada jovem e não o motivo para a esterilização. De fato, as mulheres que foram esterilizadas antes dos 30 anos iniciaram a vida reprodutiva mais cedo e quando atingiram o número de filhos desejado procuraram a esterilização.

Embora não tenha sido encontrada associação entre renda e idade ao esterilizar-se, entre as mulheres com escolaridade igual ou maior que 4

Tabela 5. Diferença entre anos de escolaridade, idade ao primeiro filho, número de filhos vivos e nivel de satisfação de acordo com a idade ao esterilizar-se, Região Metropolitana, 1992.

\begin{tabular}{lccccc}
\hline Idade da esterilização & 29 ou menos & \multicolumn{3}{c}{30 ou mais } \\
Variáveis & $N$ & 265 & 142 & \\
anos de & média & 4,4 & 3,8 & $P=0,028$ \\
escolaridade & DP & 2,80 & 2,84 & $T=2,21$ \\
\hline Idade ao & & & & \\
primeiro & $N$ & 264 & 141 & \\
filho & média & 20,1 & 22,5 & $P=0,000$ \\
& $D P$ & 2,9 & 4,2 & $T=-6,12$ \\
\hline Número de & & & & & \\
filhos & $\mathrm{N}$ & 264 & 142 & \\
vivos & média & 3,0 & 3,5 & $P=0,000$ \\
& $\mathrm{DP}$ & 0,98 & 1,3 & $\mathrm{~T}=-3,89$ \\
\hline Nivel de & & & & & \\
satisfação & $\mathrm{N}$ & 265 & 142 & \\
& média & 17,0 & 17,6 & $\mathrm{P}=0,013$ \\
& $\mathrm{DP}$ & 2,8 & 2,2 & $\mathrm{~T}=-2,50$ \\
\hline
\end{tabular}


anos, foi encontrada associação entre renda e idade ao esterilizar-se para aquelas que frequientaram a escola por 3 anos ou menos. Enquanto quase $40 \%$ daquelas que tinham sido esterilizadas antes dos 30 anos recebiam mais de um salário-mínimo, apenas $21 \%$ das que se submeteram à esterilização com 30 anos ou mais recebiam mais de um salário-mínimo per capita. Daí, conclui-se que o acesso à esterilização é menor para aquelas mulheres com menor escolaridade e menor renda (Tabela 6 ).

Foi também encontrada associação entre ter referido algum problema enquanto usava um método anticoncepcional reversível e ter sido esterilizada antes dos 30 anos (Tabela 7). Este dado leva a crer que problemas no uso de métodos reversíveis é importante fator que favorece a esterilização antes dos 30 anos.

\section{A informação e a desinformação}

A maioria das entrevistadas (73\%) refere ter sido orientada antes de submeter-se à esterilizacão. Quase todas (95\%) foram orientadas pelo médico que realizou a cirurgia. Embora seja impossível avaliar essa orientação, foi possível testar o conhecimento das entrevistadas em relação à esterilização, assim como também sobre outros métodos.

O principal objetivo ao orientar a cliente que se candidata à esterilização é informar sobre a irreversibilidade do procedimento, os possíveis efeitos colaterais e as consequiências, e apoiar o processo de decisão, já que a cirurgia implica mudança definitiva na vida reprodutiva. A reversão do procedimento implica vários fatores técnicos, alguns fora de controle médico, pois é uma cirurgia cara, delicada e na maioria das vezes inacessível. A falta de entendimento das entrevistadas sobre o caráter da cirurgia, a que foram submetidas, é um problema sério que chama a atenção.

Um conjunto de afirmações sobre a esterilização e outros métodos foi lido para as entrevistadas que responderam se concordavam ou não com as afirmações (Tabela 8).

Tabela 6. Renda familiar per capita e idade ao esterilizarse entre mulheres com 3 anos ou menos de escolaridade, Região Metropolitana, 1992.

\begin{tabular}{lccc}
\hline Renda/idade & 29 ou menos & 30 ou mais & Total \\
\hline $\begin{array}{l}\text { Menos de um } \\
\text { salário-mínimo }\end{array}$ & $\% 60,5$ & 79,1 & 80 \\
$\begin{array}{l}\text { Um salário-mí- } \\
\text { nimo ou mais }\end{array}$ & $\% 39,5$ & 20,9 & 39 \\
\hline Total & $N 76(63,9 \%)$ & $43(36,1 \%)$ & $119(100,0)$ \\
\hline$X^{2}$ Pearson= 4,28603 & GL=1 & $P=0,034843$
\end{tabular}

Tabela 7. Idade ao esterilizar-se e presença de problema ao usar um método reversível previamente.

\begin{tabular}{lccc}
\hline Idade & 29 ou menos & 30 ou mais & Total \\
\hline Sem problema & $\% 39,1$ & 53,5 & 162 \\
Com problema & $\% 60,9$ & 46,5 & 205 \\
\hline Total & $238(64,9)$ & $129(35,1)$ & $367(100,0)$ \\
\hline$X^{2}$ Pearson= 7,04786 & $G L=1$ & $P=0,00794$
\end{tabular}

Grande parte das mulheres (70\%) concordou que o único método confiável é a esterilização e que a melhor maneira de obtê-lo é através de cesariana $(82 \%)$. Metade das entrevistadas $(50,9 \%)$ acredita que a esterilização feminina é mais fácil de ser realizada do que a masculina.

Embora a maioria (66\%) tivesse concordado que a reversão é difícil, um terço das mulheres ou

Tabela 8. Conhecimento sobre os métodos anticoncepcionais reversiveis entre as mulheres esterilizadas abaixo dos 40 anos, Região Metropolitana, 1992.

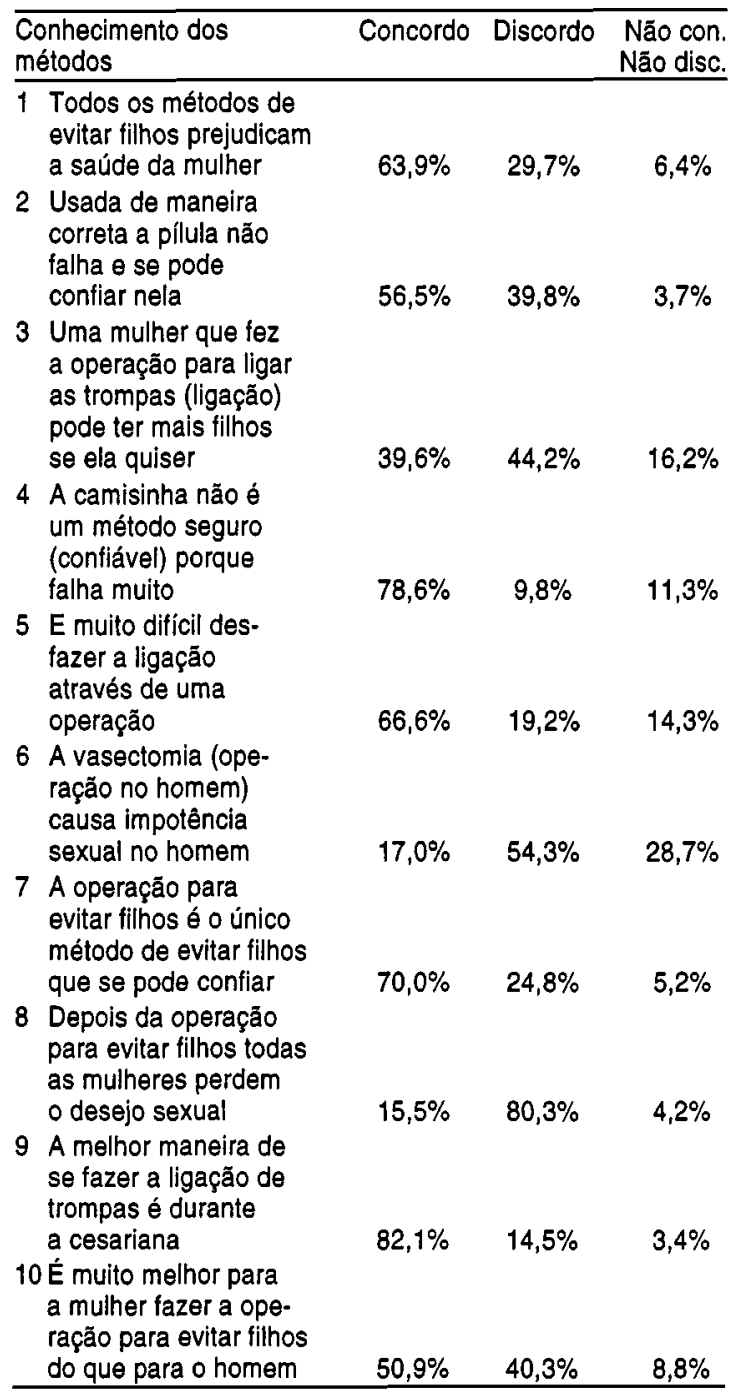


discordou (19\%) ou não sabia (14,3\%) responder a essa afirmacão. Perguntadas se a mulher esterilizada pode ter mais filhos se quiser, $40 \%$ das entrevistadas concordaram, $16 \%$ não sabiam e $44 \%$ discordaram dessa afirmação.

\section{Resultados qualitativos}

Várias entrevistadas revelaram a crença na existência de dois tipos de cirurgias. Segundo elas, a operação pode ser realizada de duas maneiras, o médico pode "cortar" ou "amarrar" as trompas. "Amarradas" estas poderão se desamarrar sozinhas após algum período de tempo (foram citados 5 e 7 anos), ou após alguma condição especial como aumento de peso. A esterilização seria de mais fácil reversão, caso a entrevistada tivesse recursos financeiros para outra cirurgia. Se a esterilização tivesse sido do tipo que as trompas foram "cortadas" a operação seria irreversível. A fonte dessa informação mais citada foi o médico, e algumas entrevistadas revelaram que a reversão foi oferecida pelo médico. Umas das entrevistadas se dizia arrependida por não ter feito a cirurgia definitiva ("a que corta") e apenas aquela que "amarra". Estas idéias são baseadas em interpretações de informações obtidas com médicos, em informações veiculadas pelos meios de comunicação e provavelmente estão também relacionadas ao baixo nível de escolaridade das entrevistadas. Pode agravar o problema o fato da esteri1ização ser chamada por vários nomes diferentes: ligação, laqueadura, operação, amarração das trompas, cirurgia de evitar filhos. São surpreendentes porque expressam uma interpretação das técnicas do procedimento sem a devida compreensão da dificuldade da reversão, de seus critérios e acesso; além do que, incluem uma certa interpretação "mágica" da técnica cirúrgica. Elas revelam a ausência do direito de obter a laqueadura, corretamente informada sobre suas conseqüências. Provavelmente a distância entre médico e paciente não permite que o entendimento seja possível entre eles. Por ter sido um fenômeno recorrente na fala das mulheres entrevistadas e entre os relatos espontâneos, além da aparente inconsistência encontrada no teste de conhecimento sobre a irreversibilidade da esterilização (Tabela 8), este dado deve ser considerado como um fenômeno de caráter cultural importante e não apenas como interpretações individuais. Já foi registrado na literatura que a desinformação sobre a irreversibilidade do procedimento também foi encontrada em outros países, especialmente entre pretos, latinos e mulheres de baixa renda (Carlson e Vicker $\left.{ }^{8}, 1982\right)$.

\section{Discussão}

O aumento da esterilização no Brasil segue o exemplo de vários países onde ela se tornou mais prevalente a partir da década de 80 , como os Estados Unidos (onde a, prevalência aumentou de $17 \%$ a $23 \%$ de 1982 a 1988 (Church e Geller $\left.{ }^{9}, 1990\right)$. No entanto, o que torna a situação brasileira curiosa é que comparada com países mais desenvolvidos, a diferença entre a prevalência da esterilização feminina e masculina é muito maior no Brasil. Quando comparado aos outros países da América Latina a sua situação também é peculiar devido à forma de disseminação, ou seja, apesar da clandestinidade, controvérsia legal, ausência de regulamentação e ausência de promoção governamental, esta prevalência é mais elevada do que em países onde a esterilização é promovida por programas de planejamento familiar, no caso do México (19\%) e Colômbia (18\%), por exemplo. O aumento da prevalência da esterilização tem sido bastante investigado e discutido por vários autores (Oliveira e Simões ${ }^{21}, 1988$; Berquó ${ }^{5,6}, 1989,1993$; Wong ${ }^{24}, 1988$ ).

A aceitabilidade da esterilização feminina é um fenômeno social importante já que mostra o alto nível de motivação das mulheres em controlar sua fertilidade. Este controle é altamente aceito pela sociedade de maneira geral, exceto por alguns setores que ainda se mostram refratários a aceitar a esterilização no país. Daí, a questão da ausência de regulamentação e a discussão da controvertida legalidade do procedimento.

$O$ presente estudo confirma que o acesso à esterilização na Região Metropolitana e provavelmente em todo Estado de São Paulo, regulado pelo pagamento do procedimento ao médico mesmo para a população pobre. Osis e col. ${ }^{22}$ (1990) referem maior facilidade para se obter a esterilização no interior do Estado. $O$ acesso à esterilização regulado por pagamento, evidentemente dificulta sua obtenção para as mulheres de menor renda. Estes resultados são consistentes com a análise de Wong ${ }^{24}$ (1988) mostrando que em São Paulo, em 1986, a pílula era mais usada entre as mulheres de baixa renda, e a prevalência da esterilização feminina aumentava com o status socioeconômico.

O pagamento como critério de acesso à esterilização havia já sido apontado por vários autores anteriormente (Janowitz e col. ${ }^{16}, 1982$; Janowitz e col. ${ }^{17}, 1985$; Lassner et col. ${ }^{18}, 1986$ e Oliveira e Simões ${ }^{21}$, 1988) e parece também ser comum em outros Estados brasileiros. Embora se saiba que em vários Estados ou cidades a presença de uma clínica privada pode facilitar o 
acesso grátis, das mulheres de baixa renda à esterilização. É o caso de alguns Estados do nordeste onde a esterilização grátis atinge índices maiores que 50\% (Oliveira e Simões ${ }^{21}, 1988$ ). Para outros Estados, entretanto, o papel dessas clínicas em disseminar a esterilização parece estar relacionado à introdução da idéia da laqueadura como escolha anticonceptiva, por exemplo através do acesso grátis e da disseminação das técnicas, como promoção de treinamentos (Badiani e col. ${ }^{4}, 1988$ ). Na Região Metropolitana, onde a pesquisa foi realizada, a maioria das esterilizações é realizada pelo médico comum sem conexão com o PAISM. O principal critério de acesso parece ser o pagamento do procedimento ao médico, embora se possa dizer que problemas de saúde aumentam a chance de obtenção de uma esterillzação grátis.

O pagamento como critério de acesso não leva em conta a necessidade da esterilização, a indicação do caso e adequação do procedimento, vedando o acesso a muitas mulheres e facilitando demais a outras. Ou seja, sem estar inserida num programa de planejamento familiar e sem estar regulamentada, a esterilização tem sido realizada sem critérios que permitam a sua escolha entre outras alternativas anticoncepcionais, e sem apoio, orientação e o devido esclarecimento para essa decisão definitiva. A realização da laqueadura sem o entendimento de sua irreversibilidade é uma consequiência deste fato. Por outro lado, o critério econômico mostra-se bastante eficaz em disseminar uma prática na qual todos aparentemente estariam ganhando: os médicos, uma recompensa financeira pelo procedimento, e as mulheres, além da esterilização, um certo status por terem pago o procedimento. A idéia "se é pago e bom para classe alta é bom para todos" pode estar relacionada à aceitação do pagamento da laqueadura. Este é o mecanismo básico através da qual esta prática se repete.

A ausência de regulamentação facilita esse sistema de recompensa ao médico que aparece como a figura que não apenas realiza o procedimento mas legitima o anseio das mulhores em controlar sua fertilidade. Este, ao contrário do marido, que muitas vezes não colabora, legitima esse desejo e torna essa opção válida, segura, eficaz e aceita. Além dos médicos, a regulamentação da esterilização também não é de interesse de muitas mulheres com condições de pagar livremente uma laqueadura sem serem questionadas sobre os critérios para indicação do procedimento. Ou seja, a combinação perfeita de proteção, à liberdade de escolha de algumas mulheres, liberdade esta movida pelo poder aquisitivo, com a liberdade de negociar o preço do seu trabalho pelos médicos mesmo que para isso se ignore os preceitos éticos.

Outros fatores políticos mais complexos, tais como a influência da Igreja católica na política de planejamento familiar do governo e outras tendências natalistas também participam das condições sob as quais esta estratégia social historicamente se criou (Merrick ${ }^{18}, 1990$ ).

A regulamentação irá evitar o abuso da esterilização, a escolha desinformada e trará a possibilidade de controle, apoio e aconselhamento durante a decisão. Entretanto, é absolutamente necessário incluir restrições que evitem a escolha inadequada da esterilização. Atrelada às atividades de planejamento familiar do PAISM, esta pode se transformar numa alternativa entre outras e melhorar a qualidade do planejamento familiar. Os médicos deveriam estar incluídos nesse processo e conscientes da necessidade de controle do procedimento. A situação de reversão desse quadro não deve ser esperada a curto prazo após a regulamentação, já que esta situação se estabeleceu há longo tempo. Devido aos interesses econômicos dos médicos, a regulamentação deveria incluir uma discussão do preço do procedimento.

$O$ estudo também confirma a necessidade das mulheres de baixa renda em controlar sua fertilidade e a dificuldade que estas encontram no uso dos métodos reversíveis, em particular da pílula, relacionada à qualidade do planejamento familiar oferecido. Este é um fator importante que leva as mulheres a esterilização antes dos 30 anos. A esterilização em mulheres jovens tem sido apontada como fator que influencia o arrependimento após a esterilização (Grubb e col. ${ }^{7}, 1985$; Boring e col. ${ }^{7}$, 1988; Marcil-Gratton ${ }^{19}, 1988$ ).

A pesquisa também revelou que a forma de orientação antes da esterilização das mulheres de baixa renda não tem sido adequada. Este fato fere preceitos éticos segundo os quais médicos e profissionais de saúde, ao prover a esterilização, devem informar corretamente e enfatizar a irreversibilidade do procedimento. A orientação da candidata à esterilização deve ser realizada por profissionais de saúde treinados para esta função. Por razões éticas a Organização Mundial de Saúde (W.H.O. ${ }^{25}$, 1992) não recomenda que médicos e outros profissionais, que recebam recompensa financeira pela realização da esterilização, estejam pessoalmente envolvidos na orientação da cliente, candidata à esterilização.

VIEIRA, E.M. [Female sterilization among low income women in a metropolitan region of southeastern Brazil and factors related to its prevalence]. Rev. Saúde Pública, 28: $440-8,1994$. A survey carried out in the metropolitan 
region of S. Paulo between March and July, 1992, shows that of 3,149 low income women aged from 15 to 49 , $21.8 \%$ had been sterilized. Of those women living in marital union $29.2 \%$ had been sterilized and $34.4 \%$ were on the pill. Four hundred and seven sterilized women under 40 years old who underwent sterilization at least one year before the interview were asked about their reproductive life, the previous use of contraception, the decision-making process regarding their sterilization, the acess to the operation and their adaptation after the operation. The results show that acess to sterilization is obtained by means of payment to the doctor even in the case of low income women. The lack of regulation of sterilization and the insuficient provision of family planning methods by the Women's Health Comprehensive Programme are probably encouraging young women to opt for sterilization. The provision of sterilization presents ethical problems. The study shows that the irreversibility of the procedure was not understood by almost $40 \%$ of the women sterilized. The acceptability of sterilization as a result of a complex social strategy involving various sectors of Brazilian society associated with the need for the control of fertility felt by women are discussed. The need to regulate and control the procedure is discussed. The regulation of sterilization would creat fairer acess to sterilization and could safeguard the ethical aspects of its choice.

Keywords: Sterilization, tubal, statistical. Family planning, methods. Women health.

\section{Referências Bibliográficas}

1. AGUINAGA, H. \& SCHIAVO, M. R. Esterilização: realidade e mito. Rio de Janeiro, The Pathfinder International, 1991 .

2. ASSEMBLÉIA LEGISLATIVA DO ESTADO DO RIO DE JANEIRO. Relatório final da Comissāo Parlamentar de Inquérito sobre Esterilização. Rio de Janeiro, 1991.

3. ASSEMBLEIA LEGISLATIVA DO ESTADO DE GOIAS. Relatório final da Comissão Parlamentar de Inquérito sobre Esterilização em Massa de Mulheres. Goiânia, 1992.

4. BADIANI, R.; GOMES, C.; ARRUDA, J.M. 0 papel dos setores público e privado como fonte de obtenção de métodos anticoncepcionais. In: Encontro Nacional de Estudos populacionais, $4^{\circ}$ Águas de São Pedro, 1984. Anais. São Paulo, 1988. v.1, p. 675-94.

5. BERQUÓ, E. A esterilização feminina hoje. Ciênc.e Tecnol., 88:598-610, 1989.

6. BERQUÓ, E. (1993) Brasil um caso exemplar, a espera de uma ação exemplar: anticoncepção e partos cirúrgicos. Campinas, 1993. [Trabalho apresentado para o seminário: A Situação da Mulher e o Desenvolvimento. Ministério das Relações Exteriores e NEPO/ UNICAMP].

7. BORING, C.C.;ROCHAT, R.W.;BECERRA, J. Sterilization regret among Puerto Rican women. Fertil. Steril.,49:973$81,1988$.

8. CARLSON, 0. \& VICKERS, C. Voluntary sterilization and informed consent: are guidelines needed? New York,
UMCNews, 1982 apud Shapiro, T.M. Population control politics: women, sterilization and reproductive choice. Philadelphia, Temple University Press, 1985

9. CHURCH, C.A. \& GELLER, J.S. Voluntary female sterilization: number one and growing. Popul. Rep., Ser. C, (10) 1990

10. CONSELHO ESTADUAL DA CONDIÇÃO FEMININA. Comissão de Saúde. Clínicas de esterilização: a quem servem? O que são e como funcionam? São Paulo, 1986.

11. CONSELHO REGIONAL DE MEDICINA DO ESTADO DE SÃO PAULO. Aspectos éticos que envolvem a esterilização. Ética Med., l(1):67, 1988.

12. O DIREITO de não ter. Veja, 29 jun. 1994, p. 96.

13. GRUBB, G.S.; PETERSON, H.B.; LAYDE, F.M.; RUBIN, G.L. Regret after decision to have a tubal ligation. Fertil.Steril., 44:248-53, 1985.

14. HARDY, E.; OSIS, M.J.D.; FAÚNDES, A.; ALVES, G.; PINOTTI, J.A. A laqueadura tubária precoce e durante a cesária: dimensões atuais e fatores que a determinam. Rev. Ginecol. Obstet., 4:70-6, 1993.

15. HAWS, J.; BAKAMJIAN, L.; WILLIAMS, T.; LASSNER, K.J. Impact of sustainability policies on sterilization services in Latin America. Stud. Family Plan., 23:8595, 1992.

16.JANOWITZ, B.; HIGGINS, J.E.; CLOPTON, D.C.; NAKAMURA, M.S.; BROWN, M.L. Acess to postpartum sterilization in Southeast Brazil. Med. Care, 20:526-34, 1982.

17. JANOWITZ, B.; HIGGINS, J.E.; RODRIGUES, W.; ARRUDA, J.M.; SMITH, J.B.; MORRIS, L. Sterilization in the Northeast of Brazil. Soc. Sci. Med., 20:215-21, 1985.

18.LASSNER, K.J.; JANOWITZ, B.; RODRIGUES, C.M.B. sterilization approval and follow-through in Brazil. Stud. Family Plan., 17: 188-98, 1986.

19. MARCIL-GRATTON, M. Sterilization regret among women in metropolitan Montreal. Family Plan. Perspect., 20:222-2, 1988.

20.MERRICK, T.M. The evolution and impact of policies on fertility and family planning: Brazil, Colombia and Mexico.In: Roberts, G. Population policy: contemporary issue. Praeger, New York, 1990. p. 147-65

21. OLIVEIRA, L.A.P. \& SIMŌES, C.C. da S. As informações sobre fecundidade, mortalidade e anticoncepção nas PNADs. In: Sawyer, D. 0. org. PNADS emfoco: anos 80. São Paulo, Associação Brasileira de Estudos Populacionais, 1988. p. 183-225.

22. OSIS, M.J.D.; HARDY, E.; SIMÕES, I.R.S.; VERA, S.; FAÚNDES, A. Laqueadura tubária nos serviços de saúde do Estado de São Paulo. Rev. Ginec. Obstet., 1:195-204, 1991.

23. VILLELA, W.V.; BARBOSA, R.M.; KALCKMANN, A.S. Avaliação do planejamento familiar na Grande São Paulo; Relatório Final. São Paulo, Instituto da Saúde, 1988.

24. WONG, L.R. A prevalência de métodos anticoncepcionais no Estado de São Paulo. Conjut. Demogr., 3, 11-22, 1988.

25. WORLDHEALTH ORGANIZATION. Female sterilization: a guide to provision of services. Geneva, 1992.

\footnotetext{
Recebido para publicação em 9.8 .1993 Reapresentado em 7.8.1994 Aprovado para publicação em 20.9.1994
} 